\title{
VRP COMPLEX NETWORK ANALYSIS AND SIMULATION
}

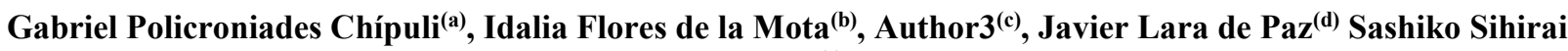 \\ $\operatorname{Reyna}^{(e)}$
}

(a),(b),(c),(d),(e) Universidad Nacional Autónoma de México

${ }^{\left({ }^{(a)} \text { gpolicroniadesch@gmail.com, }\right.}{ }^{(\mathrm{d})} \underline{\text { idalia@unam.mx, }}{ }^{\left({ }^{(c)} \text { ilaradepaz@gmail.com, }\right.}{ }^{(\mathrm{b})} \underline{\text { sashikosr@outlook.com }}$

\begin{abstract}
When carrying out a systemic analysis of a distribution network, it is possible to identify controllable and noncontrollable factors for decision makers, when the system being disaggregated into greater levels of detail, which may affect compliance with a deterministic routing plan. Some of these factors, to mention a few, may include late deliveries of raw material, unexpected transportation failures, unexpected closures of some distribution center; among others. If this type of analysis is combined with a topological analysis of the network as complex one, then it will be possible to develop more robust networks that can deal with a greater number of adversities. Identifying the topological analysis as an opportunity niche for the elaboration of possible scenarios to improve the flow through the entire network. These scenarios have been simulated in SIMIO. One way to mix both principles, is possible to find in the method proposed by authors. A case study is shown in the automotive industry.
\end{abstract}

Keywords: VRP, Complex Networks, Simulation

\section{INTRODUCTION}

The main objective of a vehicle routing problem (VRP) is the design of routes assigned to vehicles that distribute product to a group of customers; with the characteristic that each route starts and ends in the same central warehouse. This type of problem is considered as a classic problem of combinatorial optimization and due to its complexity, it is cataloged in the literature as a NPHard type problem as is mentioned in(Braekers, Ramaekers, \& Van Nieuwenhuyse, 2016; Cordeau, Laporte, Savelsbergh, \& Vigo, 2007; Mohammed et al., 2017; Parragh, Doerner, \& Hartl, 2008a, 2008b). This type of models can be solved by heuristic, metaheuristic or exact techniques; However, because one of its objectives is the optimization of resources for obtaining solutions, the preferred method is usually metaheuristic techniques; due to its quality of solution and execution time; compared to the exact techniques that provide optimal solutions at a high cost of time (Cordeau et al., 2007). An application of these models to solve a problem within a distribution network considers the clients how the vertices of the network and the arcs will rep-resent the travel or tour sections, to each of these arcs, it is assigned a cost that represents travel time or distance. The VRP as is mentioned in (Policroniades \& Flores de la Mota, 2016; Policroniades, G., Flores de la Mota, I., Sihirai Reyna, O. S., \& Lara de Paz, J., 2018) has been mainly concerned with solving problems of combinatorial optimization routing, seeking to optimize the resources used in a general way to obtain a solution. This principle can go so far as to undermine transportation models, by eliminating relationships and significant variables of reality; in order to make efficient models that can be executed in a brief moment; considering most of the time deterministic models. However, reality is not always usually this way; and stochastic events, which are not controllable for decision makers, usually occur. In many cases, within the systems, or in their environments, there are factors that are usually omitted when performing a modeling, due to the increase in complexity; both computationally and systemically. A tool that allows analyzing the system and identifying possible critical points in the distribution network, are the metrics provided by complex networks; because they allow to know and characterize the topology of a distribution network. Some of these metrics are clustering coefficients, centrality analysis, grade distribution and vulnerability analysis; among other; which will allow for example to identify where to place a Distribution Center closer to a set of customers, group customers or warehouses by common characteristics, etc. Knowing these metrics will allow the generation of scenarios that can be tested by means of simulation; to which an optimization process will be applied to identify the ideal input parameters for its correct operation. All this process is based on the methodology proposed by (Policroniades, G. et al., 2018); shown in figure 1. In this way, it can be said that the main objective of this work is to show an application of the methodology.

\section{THE PROPOSED METHODOLOGY, DESCRIPTION AND BACKGROUND}

The methodology is composed of nine stages; among which there is a process of verification and validation of the information; as shown in the figure 1 . The validation process is done both to validate the conceptual model and the simulation model. The process is shown as a cyclical 
process in which the main objective is the continuous improvement of the distribution system. The following methodology is based on (C. M. Banks, 2010; J. Banks, 1998; Barceló, Grzybowska, \& Pardo, 2007; Carson \& Maria, 1997).

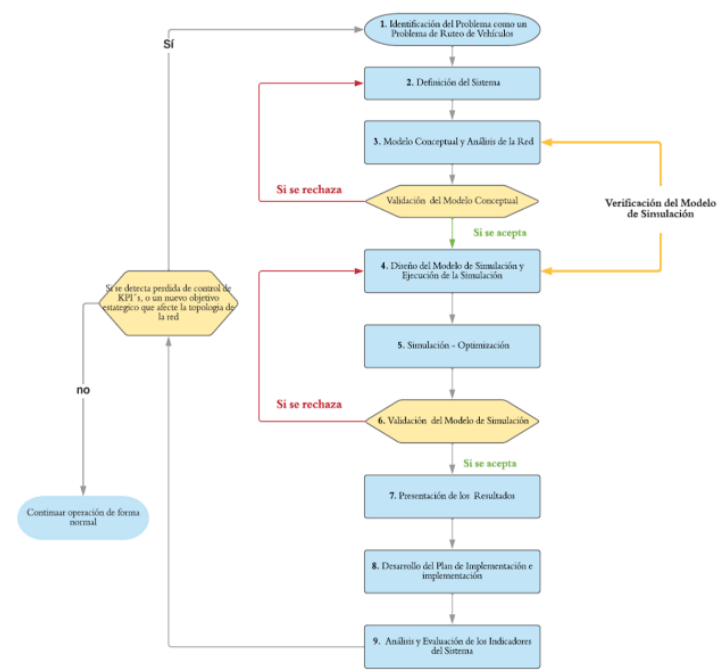

Figure 1: Proposed methodology

In general terms, it can be said that the methodology begins by identifying the problem as a vehicle routing problem by means of company indicators; subsequently, a systemic analysis stage is carried out; Once the systemic analysis is obtained, the conceptual model is constructed, and the distribution network is analyzed. With these stages, we proceed to carry out the simulation process and generate the scenarios to improve the topology of the network; just like the improvement of the process is executed. Once this stage is obtained, we proceed to simulation-optimization, the results are presented, and the solution is implemented. The process must be under constant supervision, and if possible, failures are detected, the methodology must be applied again.

The proposed methodology is made up of different methodological and technical approaches; as shown in figure 2 .

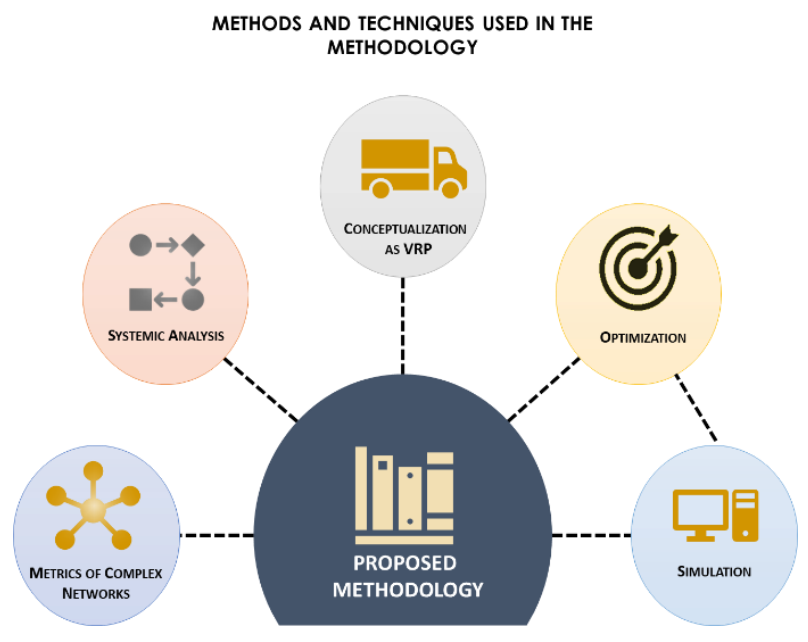

Figure 2: Proposed methodology, own design. From left to right, it can be identified the following methods and techniques:

- Complex Networks: The objective of this approach is based on the topological analysis of the distribution network; mainly aimed at identifying the vulnerability and efficiency of the network, in the face of possible attacks that may generate blockages of routes, or elimination of nodes within the network; together with an analysis of metrics that allow to quantify the coefficients of centrality, clustering, assortativity; among others (Casasnovas, 2012; Estrada, 2015).

- General systems theory: The use of this approach allows a systemic analysis to identify the restrictions, relationships, variables and functions that exist within the system. During this process, it is possible to identify internal or external elements of the system that may affect the distribution of the product throughout the network (Prawda, J., 1991; Von Bertalanffy, L., 1976).

- Vehicle Routing Problem: The core part of the methodology is to solve vehicle routing problems; for which, the specific characteristics and restrictions that allow classifying the type of vehicle routing detected in the company must be identified.

- Simulation - Optimization: This selected solution technique allows the integration of environmental or stochastic factors that cannot be integrated into deterministic models; Some of these factors may be vehicle failures, stochastic customers, stochastic demands, change of routes due to unexpected closures; among others (Berhan, Beshah, Kitaw, \& Abraham, 2014; Bertsimas, 1992; Huang, Wu, \& Ardiansyah, 2018). The concept of optimization, is linked to the VRP to find the best route that minimizes the cost function determined (Fan, Xu, \& Xu, 2009; Juan, Faulin, Pérez-Bernabeu, \& Domínguez, 2013).

In terms of the methodology approach of companies related to the automotive sector; can be mentioned the work done by (Lei, Mingfang, \& Lijun, 2012). However, when it is desired to perform a combination of the approach of the vehicle routing problem with a complex network approach; applied in a manufacturing sector, it is important to mention that the linearity of the process does not allow the existence of bifurcations in the roads, as found in other works such as (Aleta, Meloni, \& Moreno, 2016; Gallotti, Porter, \& Barthelemy, 2016); thus preventing the traditional vision of a complex network with multilayer structure as proposed (Boccaletti et al., 2014). Against this, it is proposed to use the metrics of a complex network to analyze the 
distribution network a company in this sector; emphasizing the vulnerability and efficiency metrics of the network against possible failures in nodes and arcs. These last concepts, as mentioned in (Holme, Kim, Yoon, \& Han, 2002), they can be measured through attacks directed to certain arcs or nodes

A problem of vehicle routing, as identified in (Cordeau et al., 2007) it is structured by means of a complete network; which indicates that all the elements or nodes of the network are connected to each other by means of arcs; showing an assortativity of $100 \%$. When analyzing the distribution network of a company with respect to its customers; it can be observed that this can be composed of a set of different complete networks; the way to identify each of them, lies in finding the central or regional stores that comprise it. Each of them has a specific portfolio of interconnected customers, which are served by a fleet of vehicles, forming a complete network. However, what happens in the case of one or two regional stores and a central warehouse? As shown in the following figure:

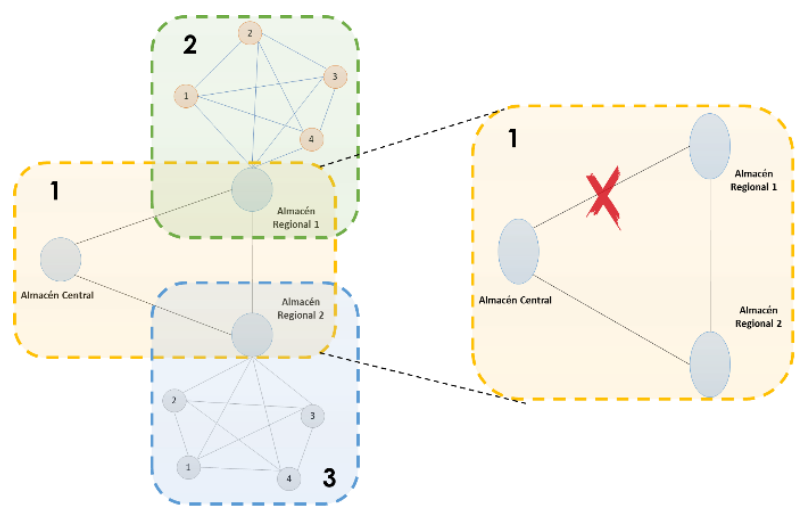

Figure 3: Example of the elimination of an arc in the distribution network, own design.

In Figure 3, there is greater vulnerability in the VRP 1 network, because there are only two different ways to get from the central warehouse to one of the other two warehouses, against the case that one of these two roads fail.

Another possible scenario to which the distribution networks are exposed, are the possible partial closures of its important nodes, as distribution warehouses or regional warehouses. When this happens, as mentioned (Cartledge \& Nelson, 2011), the arcs belonging to the failure node are disabled within the network until after the contingency causing a drastic loss of connectivity within the network.

However, it can be said that within the chain, a lower level supplier can supply its product to multiple clients with different levels within the chain; as in the case of finished products for meals; which goes directly to a dealership or automotive agency, jumping to the same OEM or manufacturer of vehicles (Braese, Niklas, 2005). In this way, it can be said that, depending on the capacity of production and distribution of the manufacturer, the product can reach a previous step to the final customer.
Each of the companies that make up the distribution chain of the automotive sector has a specific structure of its distribution network; which, depending on the consolidation mode, can be: Milk-Run, Consolidation at the Transfer Point, or Supplier Consolidation; as mentioned in (Policroniades \& Flores de la Mota, 2016). Each of these modes may vary from company to company depending on the type of contract with its customers and its facilities. However, these distribution networks due to the volume of product they handle, and the high globalization and search for emerging markets present in the same sector, make them vulnerable to possible supplier failures, change of routes, partial closure of warehouses, elimination and annexation of new clients; between another factors (Braese, Niklas, 2005).

According with all these considerations, the proposed methodology is in the process of being developed as part of a doctoral thesis project, then it will be shown the most relevant in terms of the respective progress; applied to a small case that belongs to the application case.

\section{CASE STUDY, DESCRIPTION AND APPLICATION}

The case study presented in this section is part of the distribution system of a real company of the automotive sector; which will be called as Company $\mathrm{X}$ due to confidentiality issues.

\subsection{Description of the case}

Company $\mathrm{X}$ has a Portfolio of 8 clients; which are cataloged in two regions according to their percentage of sale and distance from the central warehouse. However, despite the regions customers are served by this single store. Figure 4 shows the structure of the distribution network of company $\mathrm{X}$

The consumption behavior of these customers is determined by different statistical distributions depending on each client. The statistical distribution of the time between orders arrivals of the clients is known. These customers can be classified into three types; the first the assemblers, the second the automotive agencies and the third, the service workshops.

It has a manufacturing cell with the capacity to produce a safety belt every 4 minutes on average. In this way it can be said that a total of 15 belts can be produced for one hour; in an 8-hour working day, there will be a total production of 120 seat belts.

It has a warehouse with a maximum capacity for 250 seat belts.

It has a fleet of two vehicles with a capacity for 4 packed products; considering that each packaged product can carry 4 belts inside.

It has a sales department with a person responsible for this activity. 


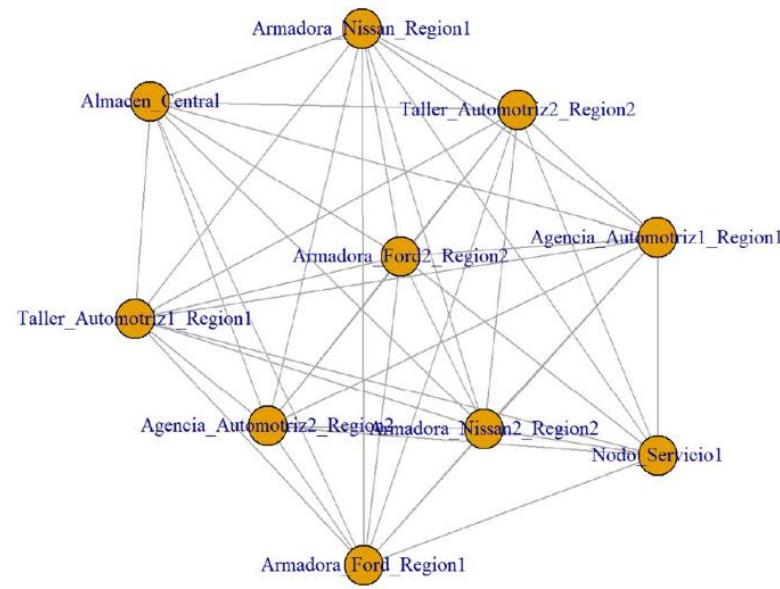

Figure 4: Company $\mathrm{X}$ distribution network, obtained through software R.

As can be observed in the first instance, there are three types of customers that depend on the central warehouse: Automotive Agencies, Service Workshops and Shippers. Each of these client's groups has their own characteristics. For example, the assembly companies, as mentioned previously, usually present a uniform behavior regarding their orders, while the other two types of clients, usually present a stochastic behavior.

Regarding to the problem; this can be classified in the following three ways:

- Shortage of Raw Material: Throughout the last 7 months the company has presented a shortage in the delivery of its raw material, despite the talks with its suppliers, this problem can be extended indefinitely due to the lack of components for its elaboration. The company has tried to find new suppliers; but it is the only provider of that type of product.

- Demand and Arrival of Orders: Because customer demand and order arrivals are stochastic, the company does not have a method to identify the best routing sequence; before which, once the loading of the vehicle is carried out, the delivery of the product begins at random, sometimes generating a greater travel distance than expected.

- Lack of Suppliers: Faced with the growing failure on the part of suppliers for the timely delivery of their product, the company considers the installation of one or two regional warehouses that can deal with possible shortages in its production area. With this alternative the warehouses must be close to the customers and source of supply; reducing the distances traveled through the entire system.

As for its routing system, each warehouse that exists in the system will control its own fleet of vehicles; an optimization must be carried out separately for each one of them. Also, it is important to mention the following characteristics of the routing problem:
- The vehicles wait for their loading capacity to be completed to start the journey to the corresponding customers. The capacity of the vehicles is maximum of 15 pallets.

- The demands that exceed the capacities of the vehicles can be divided to be sent in several vehicles.

- $\quad$ Each vehicle has a specific schedule; regarding the driver's workday. During the leisure periods, the vehicle returns to the corresponding warehouse to wait for the new start of its journey.

- Each vehicle has a failure time, due to breakdowns. Similarly, there is a repair time.

From this information, it can be said that the main objective of the company and the research to be carried out is possible to define it in the following two points:

- Find the best configuration of the network to reduce vulnerability to possible failures of the central warehouse, by annexing one or two regional warehouses strategically seeking to minimize the distance traveled in the network.

- Obtain by means of simulation - optimization a routing sequence for the vehicles that minimizes the distance traveled during the delivery process.

\subsection{Application of the Methodology}

Next, each of the stages applied to the case will be described very generally; likewise, that some of its deliverables will be addressed; mainly, with emphasis on stage III.

It is important to mention that some of the stages are carried out several times as the methodology advances to obtain their deliverables for later stages.

\subsubsection{Stage I}

The objective of the first stage is to justify the application of the methodology through the consideration of two aspects; the first of them, detecting the problem as a vehicle routing problem, through the analysis of the company's transport indicators. The second, if there is a company's goal, that implies a modification to the structure of the company's distribution network. Another important aspect of this stage is the identification of the vehicle routing problem model of the company under study.

In the case of company $X$, a main interest is seen in the reduction of its operational vulnerability by adding one or two regional warehouses to its distribution network. Then it is possible to define the following objectives:

- $\quad$ Find the best network configuration to reduce vulnerability to possible failures of the central warehouse; annexing to the system one or two regional warehouses strategically seeking to minimize the distance traveled to the interior of the network. 
- Obtain by means of simulation - optimization a routing sequence for your vehicles that minimizes the distance traveled during your delivery process.

The VRP model of company $\mathrm{X}$ can be defined as:

- A routing problem with vehicle capacity restriction (CVRP).

- Stochastic Clients.

- Stochastic Customer Demand.

- And with an inventory problem.

Once defined the objectives and the VRP model of the company; It is advisable to define a work team responsible for the application of the methodology; With these defined aspects, it is possible to carry out stage II.

\subsubsection{Stage II}

During this stage the systemic analysis of the original network and the proposed network is carried out. In the case of the proposed network, the analysis must be made to the new elements annexed to the network; as they can be: warehouses regions / Local. The objective of this stage is to identify the variables, functions, relationships and constraints of the different elements of the system. Another important aspect during this section is the adjustment and analysis of the data.

As an example of this section, table 1 is shown, where the customer's demands can be identified, and their respective distribution can be determined from the corresponding adjustment obtained through the@Risk software. It is important to mention that integer values will be considered because they represent demand values.

Table 1: Example of the parameters of the statistical distributions for the demand data obtained by the @ risk software when fitting the data.

\begin{tabular}{ccc}
\hline Client & Distribution & Parameters \\
\hline Automotive assembler & Uniform & $\alpha=3$ \\
Ford 1 & Distribution & $\beta=7$ \\
Automotive assembler & Uniform & $\alpha=2$ \\
Nissan 2 & Distribution & $\beta=4$ \\
Automotive assembler & Uniform & $\alpha=2$ \\
Ford 3 & Distribution & $\beta=7$ \\
Automotive assembler & Uniform & $\alpha=1$ \\
Nissan 4 & Distribution & $\beta=6$ \\
Automotive workshop 1 & Gamma & $\alpha=2.39$ \\
& Distribution & $\beta=5.2$ \\
Automotive workshop 2 & Gamma & $\alpha=2.21$ \\
& Distribution & $\beta=2.11$ \\
Automotive Agency & Gamma & $\alpha=2.7$ \\
Ford 1 & Distribution & $\beta=3.6$ \\
Automotive Agency & Gamma & $\alpha=2.9$ \\
Nissan 2 & Distribution & $\beta=4.3$ \\
& &
\end{tabular}

In the figure 5 the inventory process is observed and how a set of variables behaves as a function.

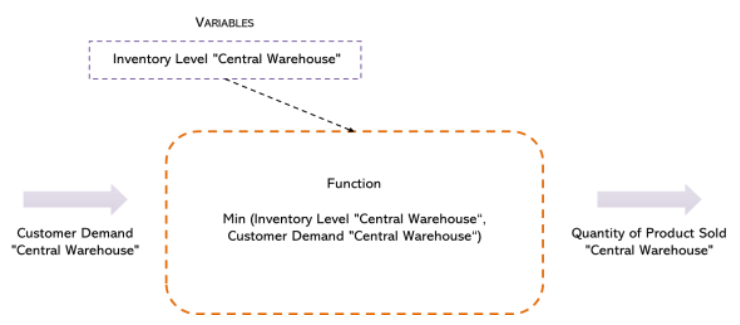

Figure 5: Example of the relationship between the variables and the calculation of a function

\subsubsection{Stage III}

This stage is divided into two main sections: in the first one, is the conceptual model. The second one is the analysis of the distribution network as well as the analysis of the different scenarios defined in stage IV when we have already one iteration. Once the analysis of the metrics is done, is time to select the best scenario that matches the objective of the project and the objective of the analysis of the metrics. With the distribution network selected, stage II is carried out to carry out the systemic analysis of the new elements of the network and the conceptual model of the first section of stage III is updated considering the new modifications of the network.

Table 2 shows the characteristics of the different scenarios obtained in stage IV, to improve the topology of the network.

Table 2: Description of the different scenarios

\begin{tabular}{cl}
\hline Scenery & \multicolumn{1}{c}{ Description } \\
\hline Scenery 1 & $\begin{array}{l}\text { Equivalent to the original network of the } \\
\text { company. }\end{array}$ \\
The existence of the two regional \\
Scenery 2 & $\begin{array}{l}\text { warehouses is considered: each of which } \\
\text { serves its four closest customers. Each region } \\
\text { has its service node for vehicles. }\end{array}$ \\
& $\begin{array}{l}\text { The two regional stores are considered; so } \\
\text { that customers are divided into two distinct } \\
\text { groups and assigned to the nearest store. }\end{array}$ \\
Scenery 3 & $\begin{array}{l}\text { Subsequently, each one of the warehouses, } \\
\text { including the central warehouse, comprises } \\
\text { two closest customers assigned to other }\end{array}$ \\
warehouses. & $\begin{array}{l}\text { Clients are accommodated by type of } \\
\text { demand; customers with more stable demand } \\
\text { are assigned to the central warehouse; while } \\
\text { the other clients are assigned to the other two } \\
\text { warehouses. } \\
\text { The use of a single regional warehouse is } \\
\text { proposed; customers with stable demand are } \\
\text { assigned central warehouse; while the other } \\
\text { clients are assigned to the new warehouse. }\end{array}$ \\
Scenary 5
\end{tabular}

Next, the corresponding summary of this stage equivalent to the original network of the company will be 
shown, as well as the respective scenarios generated in stage IV.

If the central warehouse stops working, the total distribution in the network is lost; even when in topological terms, due to the high connectivity of all the elements, vulnerability is low. Therefore, it can be said that this structure presents an operational vulnerability; which, should be minimized by means of the analysis of the different scenarios proposed in stage IV. See figure 6.

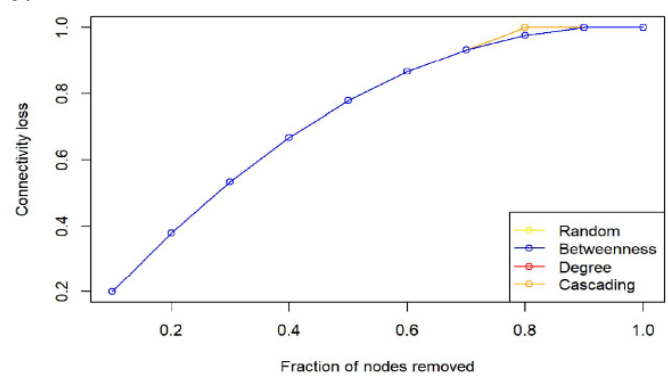

Figure 6: Company X distribution network, obtained through software R.

Vulnerability can be analyzed considering two scenarios: First eliminate two arcs randomly, see figure 7, and in the second case, the elimination of the client nodes in the network of figure 8 . As can be seen with these two possible hypothetical cases, the greatest impact on the efficiency of the network occurs with the elimination of arcs randomly since in the second place, the elimination of a node does not affect the network.

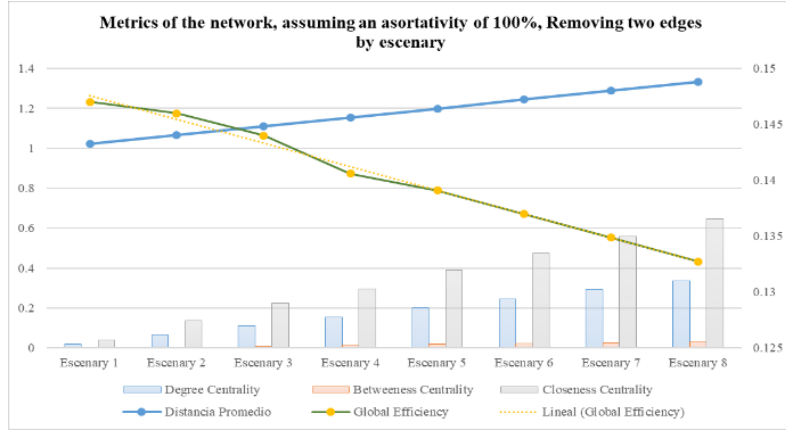

Figure 7: Behavior of the metrics of the real network, by eliminating edges from the network

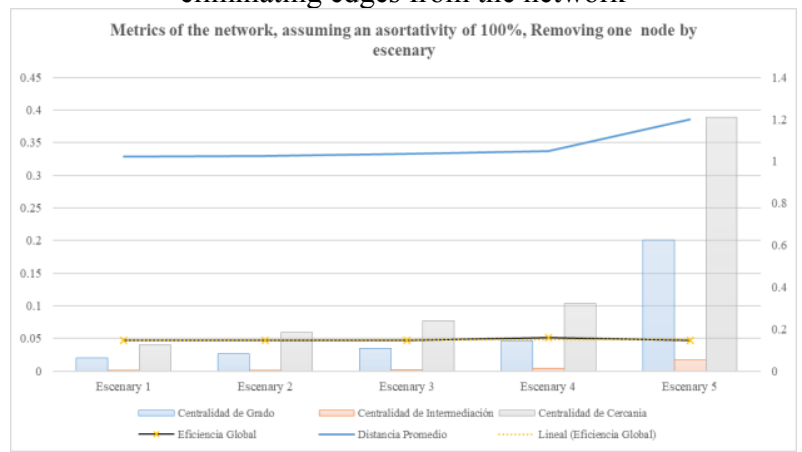

Figure 8: Behavior of the metrics of the real network, by eliminating nodes from the network
When the different scenarios generated in stage IV are analyzed, defined in table 2; Figure 9 is obtained; in which, the main metrics of each of them are represented.

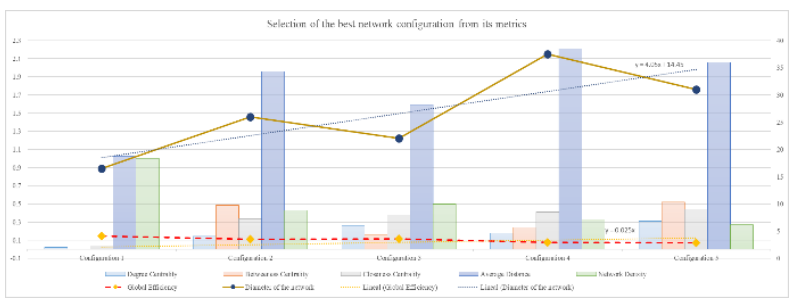

Figure 9: Metric comparison by scenario

From this figure 9, it can be said that the best selected scenario is scenario 3; because, if there is a failure of any of the supply nodes of the network, the overall impact on customers will be the minimum; this is achieved, through the concept of density.

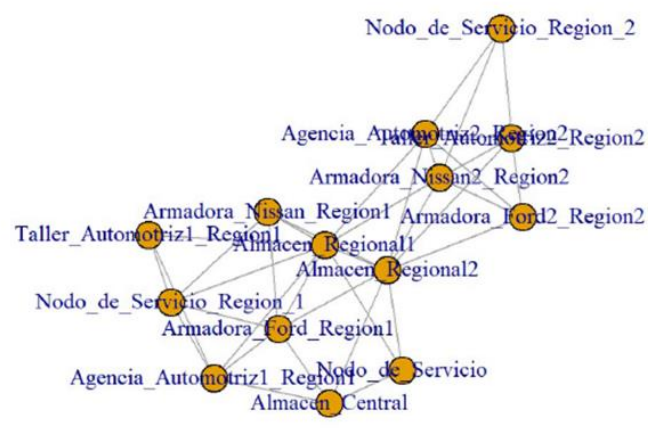

Figure 10: Proposed network of scenario 3

An important aspect to consider of the density concept; is that as a customer is attached to a new distribution warehouse; this warehouse must have enough capacity to provide the requested product. Therefore, the more connectivity there is in a network, the distribution nodes should be specialized in more customers.

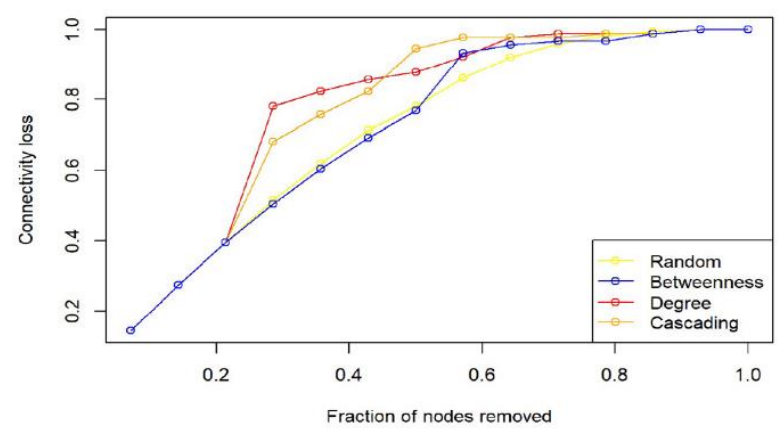

Figure 11: Vulnerability analysis for the scenario 3 network

As shown in Figure 11, when $30 \%$ of the nodes of the network are removed, it is observed how network connectivity begins to be lost; mainly because there are few connection arcs between the central warehouse and the regional warehouses. By the time one of the 
warehouses or the two regional stores is eliminated, all the arcs that depend on them are eliminated.

With this selected scenario and the current distribution network; we proceed to simulate the model and then to optimize and compare the results to verify the improvement of the distribution process.

In the research shown in this article; only the simulation reports of each of the two models will be displayed.

\subsubsection{Stage IV}

The progress of the methodology is shown until stage 4; the process of Simulation - Optimization for the proposed network and the current network is pending. The simulation was executed in Simio - Simulation software version 10.181; on a PC with an Intel core i7, 8th Generation processor.

\subsubsection{Analysis of the Original Network}

The simulation was executed considering a work week; equivalent to a total of 168 hours. During this period, it was detected that the percentages of utilization of the entities were as follows: the central depot was used during $1.58 \%$ of the time due to production; which can be observed in the following percentages:

- Production Area: $1.58 \%$ of total time.

- Waiting Area: $0.46 \%$ of total time.

- Inventory Area: $0.16 \%$ of total time.

The percentage of time of use of the vehicles is as follows: Vehicles were available $73 \%$ of the time; with respect to the $27 \%$ that elapsed in driver's rest time This percentage is because while one vehicle rests, another performs the operation; which gives a period of 84 hours per week per vehicle. This is explained as follows:

- Vehicle 1: Use $54 \%$ of time to deliver the product; the remaining time is divided between the driver's rest time and the vehicle failure time. Travel a total of $124,604 \mathrm{~km}$.

- Vehicle 2: Use $63 \%$ of total time for product delivery. The total route was $98.32 \mathrm{~km}$, practically $84 \mathrm{~km}$ less than the vehicle 1 .

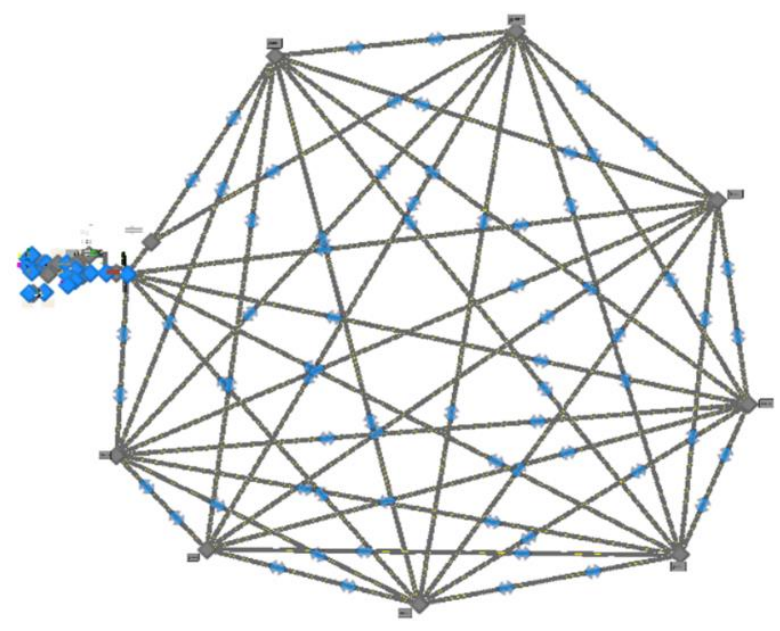

Figure 12: Current distribution network done with Simio

A total of 63 orders were received; equivalent to a total of 375 pieces of product. The entire product was delivered to the customer.

\subsubsection{Analysis of the Proposed Network}

For the following case, the same criteria were considered as in the original network; with the difference that, for each existing warehouse in the network, there is a fleet of two vehicles available with their respective work and rest hours.

Regarding the proposed network, executed during the same period, the following characteristics are detected by warehouse:

\section{Central Depot:}

- Production Area: $0.93 \%$ of total time.

- Waiting Area: $0.14 \%$ of total time.

- Inventory Area: $0.01 \%$ of total time.

The percentage of use of their vehicles is lower than that of the regional stores because this warehouse only makes deliveries when the product in the regional warehouses is exhausted; which gives a utilization of $18 \%$ with respect to $82 \%$ in leisure. As for the distance traveled on average by the two vehicles was $54 \mathrm{~km}$.

Regional Warehouse 1:

- Waiting Area: $1.32 \%$ of total time.

- Inventory Area: $0.12 \%$ of total time.

The percentage of use of their vehicles is greater than that of the central warehouse; with $61 \%$ of transport activity.

\section{Regional Warehouse2:}

- Waiting Area: $0.46 \%$ of total time.

- Inventory Area: $0.16 \%$ of total time.

The percentage of use of its vehicles is like that of regional warehouse 1 ; with the united difference that this warehouse made an average use of $67 \%$ for the transport activity. 


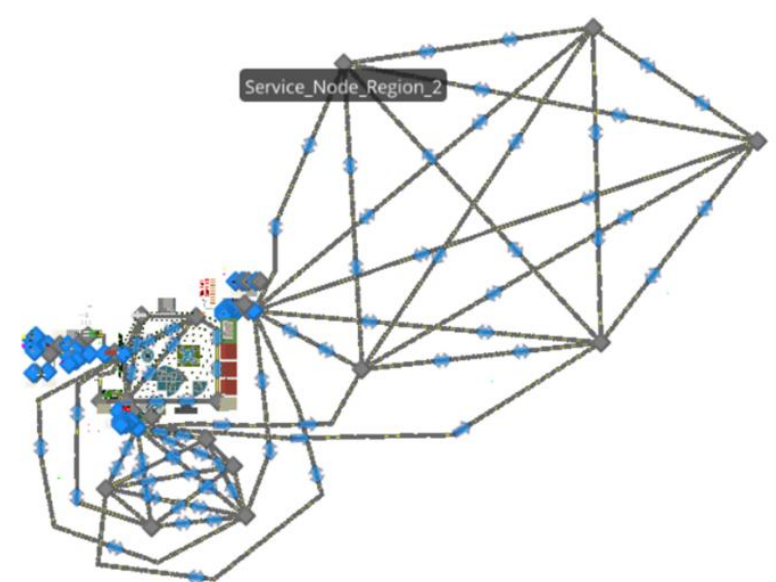

Figure 13: Proposed methodology

A total of 56 orders were received; with a total of 302 ordered products in total to the two regional warehouses. As a partial conclusion so far, it can be said that the proposed methodology allows the mixture of two approaches; the first of them, using the metrics of complex networks to analyze and reduce the vulnerability of the network, identifying the impact on customers and the operation of the network. The second approach where simulation is combined with the problem of vehicle routing through simulation optimization; allowing integrating the complexity of the environment to routing problems. An example of this in the case is the integration of the vehicles breakdowns, as well as the driver's rest time.

\section{CONCLUSIONS, EXPECTED RESULTS AND ACTIVITIES TO BE CARRIED OUT}

As a conclusion of the application of the methodology until the fourth stage, to the case of company X; it can be said that it is important to study the metrics of the network, if these are contrasted with the operational and strategic aspects of the companies. As it could be seen in the case, the analysis of vulnerability can generate confusion when there is a high connectivity and a single central warehouse.

However, what would happen to the network if that central warehouse were to fail operationally; the entire distribution chain would collapse, even when there is a high level of connectivity; because all the other nodes are client nodes and would not have the capacity to distribute the input between them. However, this controversy can be eliminated if scenarios are generated that consider these two aspects.

As advantages when performing this type of analysis; it can be mentioned that it allows to decrease the average distance traveled to the interior of the network; and explore unexplored roads or routes to reduce vulnerability through the concept of assortativity of the network.

Another measure of complex networks, for example, is the intermediation coefficient, which can be obtained globally or locally; in the case of being local, it quantifies the frequency or the number of times a node acts as a bridge along the shortest path between two other nodes. This measure can support for the location of local stores. There is a wide variety of metrics that describe the topology of the network; and its strategic use for network analysis; can help improve the performance of vehicle routing problems.

Among the activities to be carried out are the following:

- Perform a more complete analysis of the company's distribution network, including a clustering analysis for the classification and assignment of customers to regional warehouses. In the same way, through this analysis, analyze the impact of the vulnerability of the network for each of these subgroups generated.

- Execute the optimization of the network to validate the improvement of the process.

- Include all the company's clients in the study.

The expected results can be classified into:

- The methodology is expected to improve the performance of the distribution network of any company; combining two aspects: Topological and Operational.

- It will also offer the ability to integrate elements of the environment that may influence the performance of vehicle routing; as in the case of company $\mathrm{X}$, with vehicle failures.

- It will allow by means of the Simulation Optimization to obtain routing programs that improve the assignments of the vehicles to the routes established for the reduction of the costs derived from the distribution.

\section{ACKNOWLEDGMENTS}

We are grateful for the support to CONACYT for its support, likewise, we greatly thank to our advisor Ph.D. Idalia Flores de la Mota whom we greatly esteem, and we admire.

To the PAPIIT DGAPA project IT102117, UNAM for its support to this research.

\section{REFERENCES}

Aleta, A., Meloni, S., \& Moreno, Y. (2016). A multilayer perspective for the analysis of urban transportation systems. arXiv:1607.00072 [cond-mat, physics:physics]. Recuperado de http://arxiv.org/abs/1607.00072

Banks, C. M. (2010). Introduction to Modeling and Simulation. En Modeling and Simulation Fundamentals (pp. https://doi.org/10.1002/9780470590621.ch1

Banks, J. (1998). Wiley: Handbook of Simulation: Principles, Methodology, Advances, Applications, and Practice - Jerry Banks. Recuperado 
http://www.wiley.com/WileyCDA/WileyTitle/ productCd-0471134031.html

Barceló, J., Grzybowska, H., \& Pardo, S. (2007). Vehicle Routing And Scheduling Models, Simulation And City Logistics. En Operations Research/Computer Science Interfaces Series. Dynamic Fleet Management (pp. 163-195). https://doi.org/10.1007/978-0-387-71722-7_8

Berhan, E., Beshah, B., Kitaw, D., \& Abraham, A. (2014). Stochastic Vehicle Routing Problem: A Literature Survey. Journal of Information \& Knowledge Management, 13(03), 1450022. https://doi.org/10.1142/S0219649214500221

Bertsimas, D. J. (1992). A Vehicle Routing Problem with Stochastic Demand. Operations Research, 40(3), 574-585. https://doi.org/10.1287/opre.40.3.574

Boccaletti, S., Bianconi, G., Criado, R., del Genio, C. I., Gómez-Gardeñes, J., Romance, M., ... Zanin, M. (2014). The structure and dynamics of multilayer networks. Physics Reports, 544(1), $1-122$.

https://doi.org/10.1016/j.physrep.2014.07.001

Braekers, K., Ramaekers, K., \& Van Nieuwenhuyse, I. (2016). The vehicle routing problem: State of the art classification and review. Computers \& Industrial Engineering, 99, 300-313. https://doi.org/10.1016/j.cie.2015.12.007

Braese, Niklas. (2005). The Dynamics of Supply Chains in the Automotive Industry. Massachusetts Institute of Technology.

Carson, Y., \& Maria, A. (1997). Simulation Optimization: Methods And Applications. 118126. Recuperado de https://www.computer.org/csdl/proceedings/ws c/1997/4278/00/42780118.pdf

Cartledge, C. L., \& Nelson, M. L. (2011). Connectivity Damage to a Graph by the Removal of an Edge or a Vertex. arXiv:1103.3075 [cs]. Recuperado de http://arxiv.org/abs/1103.3075

Casasnovas, D. J. P. (2012). Some Basic Concepts on Complex Networks and Games. En Springer Theses. Evolutionary Games in Complex Topologies (pp. 9-46). https://doi.org/10.1007/978-3-642-30117-9_2

Cordeau, J.-F., Laporte, G., Savelsbergh, M. W. P., \& Vigo, D. (2007). Chapter 6 Vehicle Routing. En C. B. and G. Laporte (Ed.), Handbooks in Operations Research and Management Science (pp. 367-428). https://doi.org/10.1016/S09270507(06)14006-2

Estrada, E. (2015). Introduction to Complex Networks: Structure and Dynamics. En J. Banasiak \& M. Mokhtar-Kharroubi (Eds.), Evolutionary Equations with Applications in Natural Sciences (pp. 93-131). https://doi.org/10.1007/978-3-319-11322-7_3

Fan, W., Xu, H., \& Xu, X. (2009). Simulation on vehicle routing problems in logistics distribution. COMPEL - The international journal for computation and mathematics in electrical and electronic engineering, 28(6), 1516-1531. https://doi.org/10.1108/03321640910992056

Gallotti, R., Porter, M. A., \& Barthelemy, M. (2016). Lost in transportation: Information measures and cognitive limits in multilayer navigation. Science Advances, 2(2), e1500445. https://doi.org/10.1126/sciadv.1500445

Holme, P., Kim, B. J., Yoon, C. N., \& Han, S. K. (2002). Attack vulnerability of complex networks. Physical Review. E, Statistical, Nonlinear, and Soft Matter Physics, 65(5 Pt 2), 056109. https://doi.org/10.1103/PhysRevE.65.056109

Huang, K., Wu, K.-F., \& Ardiansyah, M. N. (2018). A stochastic dairy transportation problem considering collection and delivery phases. Transportation Research Part E: Logistics and Transportation Review. https://doi.org/10.1016/j.tre.2018.01.018

Juan, A. A., Faulin, J., Pérez-Bernabeu, E., \& Domínguez, O. (2013). SimulationOptimization Methods in Vehicle Routing Problems: A Literature Review and an Example. En Lecture Notes in Business Information Processing. Modeling and Simulation in Engineering, Economics, and Management (pp. 115-124). https://doi.org/10.1007/978-3-642-38279-6_13

Lei, W., Mingfang, G., \& Lijun, W. (2012). The Directed Complex Network Application in the Supply Chain. 2012 Third International Conference on Digital Manufacturing Automation, 911-914. https://doi.org/10.1109/ICDMA.2012.215

Mohammed, M. A., Ghani, M. K. A., Hamed, R. I., Mostafa, S. A., Ahmad, M. S., \& Ibrahim, D. A. (2017). Solving Vehicle Routing Problem by Using Improved Genetic Algorithm for Optimal Solution. Journal of Computational Science. https://doi.org/10.1016/j.jocs.2017.04.003

Parragh, S. N., Doerner, K. F., \& Hartl, R. F. (2008a). A survey on pickup and delivery problems. Journal Für Betriebswirtschaft, 58(2), 81-117. https://doi.org/10.1007/s11301-008-0036-4

Parragh, S. N., Doerner, K. F., \& Hartl, R. F. (2008b). A survey on pickup and delivery problems. Journal Für Betriebswirtschaft, 58(1), 21-51. https://doi.org/10.1007/s11301-008-0033-7

Policroniades, G., \& Flores de la Mota, I. (2016). State of the Art of the Different Models of Transportation Most Used in the Supply Chain of Automotive Industry. International Journal of Combinatorial Optimization Problems and Informatics, 7(3), 44-53.

Policroniades, G., Flores de la Mota, I., Sihirai Reyna, O. S., \& Lara de Paz, J. (2018). The Vehicle Routing Problem Complex Network Analysis. Journal of Applied Mathematics and Computation, 2(12). https://doi.org/10.26855/jamc.2018.12.001 
Prawda, J. (1991). Metodos y modelos de investigacion de operaciones. Vol I-II (Decima). Recuperado de https://www.iberlibro.com/Metodosmodelos-investigacion-operaciones-Vol-III/10051661077/bd

Von Bertalanffy, L. (1976). TEORIA GENERAL DE LOS SISTEMAS. Recuperado de http://www.gandhi.com.mx/teoria-general-delos-sistemas

\section{AUTHORS BIOGRAPHY}

Gabriel Policroniades Chípuli Studied Industrial Engineering at Technological Institute and Superior Studies of Monterrey, Campus Toluca (ITESM, Campus Toluca), he studied an engineering mastery with operation research orientation and has advanced metrology studies for the calculation of uncertainty, and knowledge of Lean Six Sigma Black Belt and Logistics and supply chain Currently he is studying a Ph.D. in Operation Research at UNAM.

Idalia Flores de la Mota She received her Ph.D. in Operations Research at the Faculty of Engineering of the UNAM. She graduated Master with honors and received the Gabino Barreda Medal for the best average of her generation. She has been a referee and a member of various Academic Committees at CONACYT. She has been a referee for journals such as Journal of Applied Research and Technology, the Center of Applied Sciences and Technological Development, UNAM and the Transactions of the Society for Modeling and Simulation International. Her research interests are in simulation and optimization of production and service systems. She is a full-time professor at the Postgraduate Program at UNAM.

Javier Lara de Paz studied Physics at the Faculty of Science of National Autonomous University of Mexico (UNAM), a Specialization in Applied Statistics at the UNAM. He studied his Master's degree in Operation Research at the Faculty of Engineering of the UNAM. He has been professor of Science at the and Operation Research professor at the Engineering School at the UNAM. Currently he is studying a Ph.D. in Operational Research at UNAM.

Sashiko Shirai obtained her bachelor's in actuarial science in the Faculty of Science of the UNAM. She is studying her Master in Operations Research in the Faculty of Engineering of the UNAM with the CONACYT scholarship. She is an assistant professor at the Faculty of Engineering and the Faculty of Science. Her research interests lie in complex networks, statistics and operational research. 